\title{
Expression pattern of neural synaptic plasticity marker-Arc in different brain regions induced by conditioned drug withdrawal from acute morphine-dependent rats
}

\author{
Mu LI, Yuan-yuan HOU, Bin LU, Jie CHEN, Zhi-qiang CHI, Jing-gen LIU*
}

State Key Laboratory of Drug Research, Shanghai Institute of Materia Medica, Shanghai Institutes for Biological Sciences, Chinese Academy of Sciences, Shanghai 201203, China

\begin{abstract}
Aim: The immediate early gene Arc (activity-regulated cytoskeletal-associated protein) mRNA and protein are induced by strong synaptic activation and rapidly transported into dendrites, where they localize at active synaptic sites. Thus, the Arc mRNA and protein are proposed as a marker of neuronal reactivity to map the neural substrates that are recruited by various stimuli. In the present study, we examined the expression of Arc protein induced by conditioned naloxone-precipitated drug withdrawal in different brain regions of acute morphine-dependent rats. The objective of the present study was to address the specific neural circuits involved in conditioned place aversion (CPA) that has not yet been well characterized.

Methods: Place aversion was elicited by conditioned naloxone-precipitated drug withdrawal following exposure to a single dose of morphine. An immunohistochemical method was employed to detect the expression of Arc, which was used as a plasticity marker to trace the brain areas that contribute to the formation of the place aversion.

Results: Marked increases in Arc protein levels were found in the medial and lateral prefrontal cortex, the sensory cortex, the lateral striatum and the amygdala. This effect was more pronounced in the basolateral amygdala (BLA), the central nucleus of the amygdala (CeA), and the bed nucleus of the striatal terminals (BNST) when compared with the control group.

Conclusion: Our results suggest that these brain regions may play key roles in mediating the negative motivational component of opiate withdrawal.
\end{abstract}

Keywords: negative reinforcing effects; withdrawal; conditioned place aversion; Arc; prefrontal cortex; striatum; amygdala; rats Acta Pharmacologica Sinica (2009) 30: 282-290; doi: 10.1038/aps.2009.10

\section{Introduction}

In opiate-dependent rats, naloxone-precipitated withdrawal induces the emergence of a negative affective state ${ }^{[1]}$. A desire to avoid this aversive state is proposed to contribute to compulsive drug use $\mathrm{e}^{[2]}$. The most sensitive behavioral index reflecting the negative motivational aspect of withdrawal is naloxone-induced conditioned place aversion $(\mathrm{CPA})^{[3,4]}$. CPA is a Pavlovian conditioning paradigm in which morphine withdrawal is paired with a particular environment, which triggers the onset of association between the negative affective consequences of withdrawal and the context. When the animals are re-exposed to the paired environ-

* Correspondence to Prof Jing-gen LIU.

E-mail jgliu@mail.shcnc.ac.cn

Received 2008-12-06 Accepted 2009-01-16 ment in a drug-free state, they avoid the paired environment due to the association between the context and aversive memories of drug withdrawal. CPA can be clearly elicited in both acute and chronic opiate-dependent rats by naloxoneprecipitated drug withdrawal ${ }^{[3-6]}$. Moreover, recent studies demonstrated that conditioned place aversion was elicited by low doses of naloxone following a single dose of morphine after only one pairing ${ }^{[5-7]}$. However, the neural substrates underlying the motivational component of opiate withdrawal remain unclear. An understanding of the neural substrates involved in the formation of negative affective memories of opiate withdrawal might provide important clues about opioid addiction.

Changes in synaptic plasticity are implicated in a range of adaptive brain responses, including memory formation, mood stability, and drug addiction ${ }^{[8,9]}$. The expres- 
sion of specific immediate-early genes (IEGs) is induced by neural activity that produces stable changes in synaptic plasticity ${ }^{[10,11]}$ and by behavioral training ${ }^{[12-15]}$. Increasing evidence suggests that the immediate early gene Arc, also termed Arg 3.1 $1^{[16]}$, is critically involved in processes of synaptic plasticity that are induced by activity and some forms of behavioral memory ${ }^{[17]}$. A specialized role of Arc in synaptic plasticity is implied by the fact that Arc mRNA is enriched in dendrites of neurons, where it associates with cytoskeletal proteins $^{[18]}$, and that its mRNA and protein accumulate in dendrites at sites of recent synaptic activity ${ }^{[19]}$. Therefore, the Arc mRNA and protein are proposed as a marker of neuronal reactivity to map the neural substrates that are recruited by various stimuli.

To determine the neurobiological pathways underlying the motivational components of morphine withdrawal, we examined Arc protein expression in different rat brain regions (eg, prefrontal cortex, hippocampus, striatum, nucleus accumbens, amygdala, motor cortex and sensory cortex) in response to conditioned drug withdrawal of acute morphinedependent rats by immunohistochemistry. We revealed the spatial profile of Arc expression in different brain regions induced by naloxone-precipitated drug withdrawal following acute morphine treatment. These results indicate that conditioned morphine withdrawal can drive activity changes in specific neuronal populations of interconnected limbic areas known to be involved in aversive motivational processes.

\section{Materials and methods}

Animals Adult male Sprague Dawley rats weighing 180$300 \mathrm{~g}$ were provided by the Laboratory Animal Center, Chinese Academy of Sciences (Shanghai, China). All animals were housed in groups in a temperature-controlled room on a 12-h light/12-h dark cycle (lights on at 7:00 AM). Rats were allowed ad libitum access to food and water. All animals were treated strictly in accordance with the US National Institutes of Health Guide for the Care and Use of Laboratory Animals.

Drugs Morphine hydrochloride (98\% purification) was obtained from Qinghai Pharmaceutical General Factory (Qinghai, China). Naloxone hydrochloride was purchased from Sigma (St Louis, MO, USA). Both compounds were diluted in $0.9 \%$ sodium chloride solution and injected subcutaneously. Mouse anti-Arc antibody was purchased from Santa Cruz Biotechology, Inc (Santa Cruz, CA). Biotinylated goat anti-mouse $\mathrm{IgG}$, the $\mathrm{SABC}$ kit and the $\mathrm{DAB}$ kit were purchased from Wuhan Boster Biological Technology, Ltd (Wuhan, China).
Apparatus Conditioning occurred in a two-chamber apparatus consisting of two large compartments $(55 \mathrm{~cm} \times 22$ $\mathrm{cm} \times 27 \mathrm{~cm})$ separated by a moving board $(22 \mathrm{~cm} \times 27 \mathrm{~cm})$. The two compartments had different tactile and visual cues: one chamber had a black plastic grid floor and gray walls; the other chamber had a flat black floor and white walls with black stripes. These distinctive tactile and visual stimuli served as the conditioning cues.

Conditioned place aversion The aversive conditioning procedure used has been described previously ${ }^{[4,7]}$. Animals experienced a pre-conditioning habituation to the apparatus. During the habituation, baseline preferences were assessed by placing the rats in the apparatus and allowing free access to all compartments for $15 \mathrm{~min}$. The amount of time spent in each compartment was recorded. The initial bias for either compartment was eliminated from the study. Conditioning occurred over the next 2 days. Rats were divided into a saline/saline-paired group and a morphine/naloxone-paired group, such that each group had an equal mean initial time spent in each compartment. The saline/saline-paired group served as a control.

On the first day, the morphine/naloxone-paired rats were assigned to receive saline and then returned to the home cage. Four hours later, they were given saline and then immediately confined to one of the two compartments, either the grid-floor chamber or the flat-floor chamber (in a counterbalanced manner), for $30 \mathrm{~min}$. This compartment was referred to as the "nontreatment-paired compartment". On d 2, rats were injected with $10 \mathrm{mg} / \mathrm{kg}$ of morphine (sc) and then returned to the home cage. Four hours later, they were given $0.3 \mathrm{mg} / \mathrm{kg}$ naloxone (sc) and immediately placed in the compartment opposite to that used on $\mathrm{d} 1$ for $30 \mathrm{~min}$. This compartment was referred to as the "treatment-paired compartment". Twenty-four hours after the conditioning trial, all rats were allowed to freely explore the entire apparatus for $15 \mathrm{~min}$, and the amount of time spent in each compartment was measured. CPA scores represented the time spent in the treatment-paired compartment minus the time spent in the nontreatment-paired compartment during the place aversion test.

For immunohistochemical detection, rats were perfused immediately when they were removed from the treatmentpaired compartment on the second day of CPA conditioning.

Immunohistochemistry of Arc Brain sections from different groups were processed in parallel to minimize the variations in immunohistochemical labeling. Rats were quickly anesthetized with sodium pentobarbital $(55 \mathrm{mg} / \mathrm{kg})$ before perfusion. For light microscopy, deeply anesthetized rats were perfused with saline and then $4 \%$ cold paraformal- 
dehyde in $0.1 \mathrm{~mol} / \mathrm{L}$ phosphate buffer. Brains were removed from the skulls and post-fixed in $4 \%$ paraformaldehyde overnight at $4{ }^{\circ} \mathrm{C}$. The next day, the brains were transferred to a solution of $30 \%$ sucrose overnight until they sank. Cryostat sections of the brain were then cut at a thickness of $30 \mu \mathrm{m}$ and processed using standard immunocytochemical methods, as previously described in detail ${ }^{[18]}$. All washes were conducted in $0.1 \mathrm{~mol} / \mathrm{L}$ phosphate buffer, and sections were blocked with $10 \%$ normal goat serum for $2 \mathrm{~h}$ at room temperature. Sections were incubated overnight in primary antibody (mouse anti-Arc antibody, 1:500 dilution in 10\% normal goat serum) at $4{ }^{\circ} \mathrm{C}$. Then sections were incubated with secondary antibody (biotinylated goat anti-mouse IgG, 1:200 dilution in 10\% normal goat serum) for $2 \mathrm{~h}$ at room temperature. Arc-positive sites were visualized using a SABC kit and a DAB kit employing 0.1\% 3,3'-diaminobenzidine as the chromogen. In control sections in which the primary antibodies were omitted or replaced by nonimmune rabbit or goat serum, no stained cells were seen. The brain slices were subsequently dehydrated in alcohol and xylene and coverslipped. Finally, they were imaged on an Olympus IX51 microscope.

In order to quantitatively examine the protein expression data, fields measuring $200 \times$ magnification in the brain slices were digitally captured and the integrated optical density (IOD) of positive cells was automatically counted using Image Pro Plus software.

Statistical analysis All data are represented as the mean \pm SEM. Statistical comparisons between two experimental groups were conducted using unpaired Student's $t$ tests. When more than two groups were compared, a oneway analysis of variance (ANOVA), followed by NewmanKeuls test, was used. The significance level was set at $P<0.05$.

\section{Results}

Place aversion induced by naloxone in single-dose morphine-treated rats Previous studies showed that a significant place aversion could be conditioned by naloxoneprecipitated withdrawal following either acute or chronic morphine treatments. Recent studies demonstrated that conditioned place aversion was elicited by low doses of naloxone following a single dose of morphine after only one pairing $^{[5-7]}$. In the present study, we employed a similar training paradigm, in which CPA was induced by administration of naloxone $(0.3 \mathrm{mg} / \mathrm{kg}, \mathrm{sc}) 4 \mathrm{~h}$ after a single exposure to morphine $(10 \mathrm{mg} / \mathrm{kg}, \mathrm{sc})$, as reported in previous studies ${ }^{[4-7]}$. Consistent with previous studies, one pairing with naloxone following a single dose of morphine exposure produced sig- nificant aversion for the withdrawal-associated environment in morphine-treated rats. In Figure 1, rats pretreated with a single dose of morphine followed by one pairing with naloxone spent significantly less time in the compartment that was paired with morphine withdrawal compared with rats pretreated with saline followed by a pairing with saline (aversion score: $-407 \pm 27 v s-70 \pm 52$ s, $P<0.01)$. Such enhanced aversion is thought to reflect the negative motivational and affective state associated with morphine withdrawal ${ }^{[20]}$. However, rats pretreated with a single dose of saline followed by one pairing with naloxone did not demonstrate a significant place aversion compared with rats pretreated with saline followed by a pairing with saline. Additionally, rats pretreated with a single dose of morphine followed by one pairing with saline also failed to demonstrate a significant CPA (data submitted to another journal). Previous studies have also demonstrated that naloxone administration in the absence of morphine pretreatment and morphine treatment without naloxone precipitation failed to produce place aversion ${ }^{[4-7]}$.

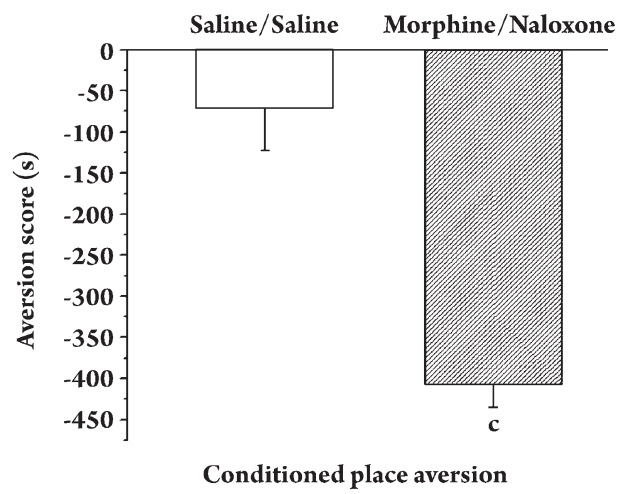

Figure 1. Bar graph showing place aversion produced by one pairing with naloxone in acute morphine treated rats. Each bar represents the aversion score (mean \pm SEM) in seconds spent in the treatmentpaired compartment minus the mean time in seconds spent in the nontreatment-paired compartment during the place preference test. Animals spent significantly less time in the naloxone-paired chamber after one pairing with naloxone at dose of $0.3 \mathrm{mg} / \mathrm{kg}, n=8 .{ }^{c} P<0.01 v \mathrm{~s}$ saline/saline.

Arc expression in different brain regions in response to naloxone-precipitated morphine withdrawal from single-dose morphine-treated rats To identify the neural circuits that are recruited by conditioned naloxoneprecipitated morphine withdrawal, we examined the effects of conditioned naloxone-precipitated morphine withdrawal on Arc protein expression in the brains of acute morphinedependent rats by immunohistochemistry (Figure 2). Because previous studies have suggested that the timepoint 


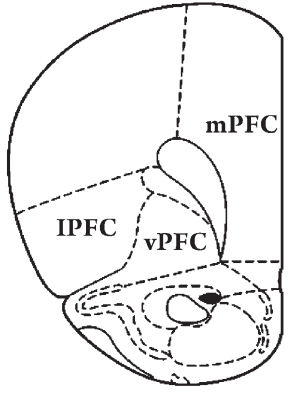

Bregma $3.20 \mathrm{~mm}$

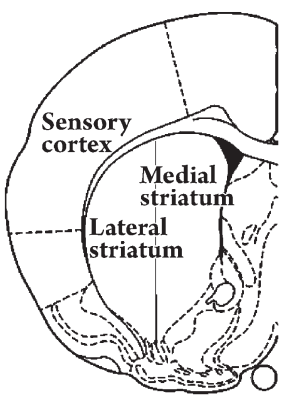

Bregma $0.2 \mathrm{~mm}$

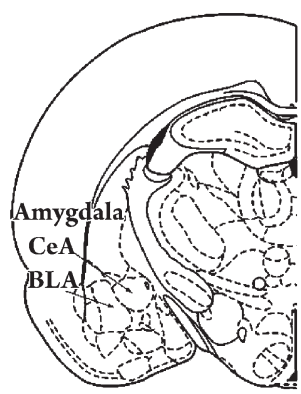

Bregma $-2.8 \mathrm{~mm}$

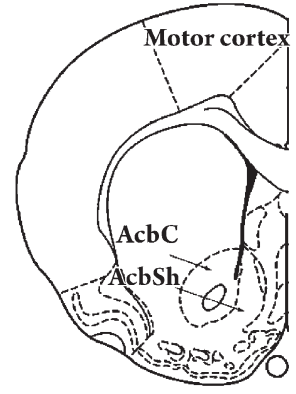

Bregma $1.0 \mathrm{~mm}$

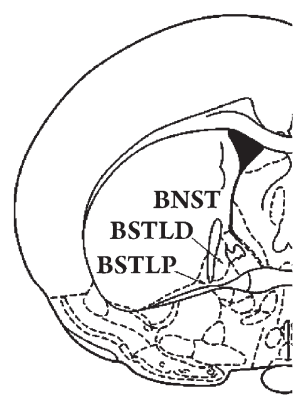

Bregma $-0.26 \mathrm{~mm}$

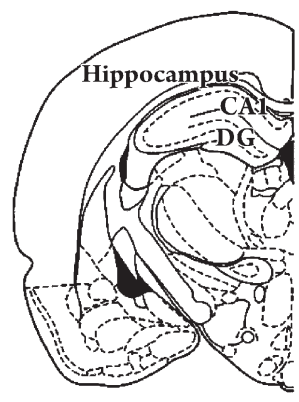

Bregma $-3.6 \mathrm{~mm}$
Figure 2. Brain areas of rat analyzed in this study: mPFC, IPFC and vPFC of prefrontal cortex; AcbC and AcbSh of nucleus accumbens; medial and lateral striatum, BNST, CeA and BLA of amygdala; CA1 and DG of hippocampus; motor cortex and sensory cortex. Bregma coordinates were inferred from the brain atlas of Paxinos and Wastson (1997).

of $30 \mathrm{~min}$ is optimal for detecting Arc mRNA and protein expression $^{[21-23]}$, we used this timepoint in the present study. A representative immunohistochemical staining of Arc protein is shown in Figure 3. Positive staining of Arc protein was clearly visualized at the dendrites and soma of neurons (Figure 4). Quantitative analysis was performed on the PFC, cortex, striatum, nucleus accumbens, amygdala, and hippocampus (Figure 5), which were selected on the basis of their possible involvement in the motivational components of the opiate withdrawal syndrome. Conditioned naloxoneprecipitated morphine withdrawal induced an increase in Arc protein expression in a number of brain regions (Figure 3A;
Table 1. Regional Arc protein expression $30 \mathrm{~min}$ after the conditioned place aversion training in groups of acute saline/saline paired and morphine/naloxone paired rats. Values-integrated optical density (IOD) represented mean \pm SEM. $n=4 .{ }^{b} P<0.05,{ }^{c} P<0.01$ significant different from acute saline/saline paired and morphine/naloxone paired rats.

\begin{tabular}{lcc}
\hline Brain areas & $\begin{array}{c}\text { Morphine/ } \\
\text { naloxone paired }\end{array}$ & Saline/saline paired \\
\hline mPFC & $863.40 \pm 145.03^{\mathrm{b}}$ & $400.93 \pm 116.22$ \\
IPFC & $1640.23 \pm 197.19^{\mathrm{c}}$ & $178.60 \pm 67.06$ \\
vPFC & $1396.36 \pm 251.70$ & $805.05 \pm 177.03$ \\
Motor cortex & $564.79 \pm 64.50$ & $363.16 \pm 112.21$ \\
Sensory cortex & $1031.77 \pm 204.97^{\mathrm{c}}$ & $93.82 \pm 44.62$ \\
NAc shell & $213.28 \pm 52.02$ & $269.65 \pm 114.28$ \\
NAc core & $299.40 \pm 35.93$ & $254.22 \pm 45.19$ \\
DMS & $119.41 \pm 14.64$ & $80.09 \pm 13.73$ \\
DLS & $263.59 \pm 61.52^{\mathrm{c}}$ & $13.93 \pm 3.50$ \\
BLA & $1241.91 \pm 254.96^{\mathrm{b}}$ & $431.07 \pm 23.51$ \\
CeA & $669.57 \pm 43.29^{\mathrm{c}}$ & $78.05 \pm 7.60$ \\
BNST & $358.43 \pm 55.24^{\mathrm{c}}$ & $4.75 \pm 2.21$ \\
CA1 & $376.31 \pm 41.35$ & $289.50 \pm 89.63$ \\
DG & $238.14 \pm 41.87$ & $218.75 \pm 40.59$ \\
\hline
\end{tabular}

Fourteen brain areas were measured at various levels from bregma (Paxinos and Waston, 1997)

Table 1). However, the degree of increase varied across these brain regions. For instance, a remarkable increase of Arc protein expression was detected in the IPFC, DLS, BNST, $\mathrm{CeA}$ and sensory cortex after an injection of naloxone of 0.3 $\mathrm{mg} / \mathrm{kg}(P<0.01)$, and a significant increase in Arc protein expression was detected in the BLA and $\mathrm{mPFC}(P<0.05$, Figure 3A; Figure 5; Table 1). In contrast, a number of other brain regions, including vPFC, NAc, DMS, the hippocampus, and motor cortex, showed undetectable changes in Arc protein expression in response to naloxone-precipitated morphine withdrawal (Figure 3B; Figure 5; Table 1). Administration of morphine $(10 \mathrm{mg} / \mathrm{kg})$ alone without conditioned naloxone precipitation or injection of naloxone $(0.3$ $\mathrm{mg} / \mathrm{kg}$ ) without pretreatment with morphine failed to induce an increase in Arc protein expression in detected brain regions (Figure 6). These results clearly indicate that conditioned naloxone-precipitated morphine withdrawal results in an alteration of Arc protein expression.

\section{Discussion}

Recently, the negative reinforcement mechanisms underlying opiate addiction have received considerable attention $^{[2,24]}$. It was suggested that the maintenance of compulsive drug use was substantially associated with 
A
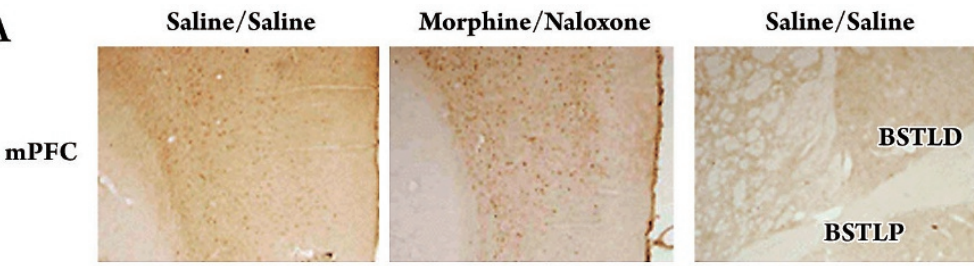

Morphine/Naloxone

PFC
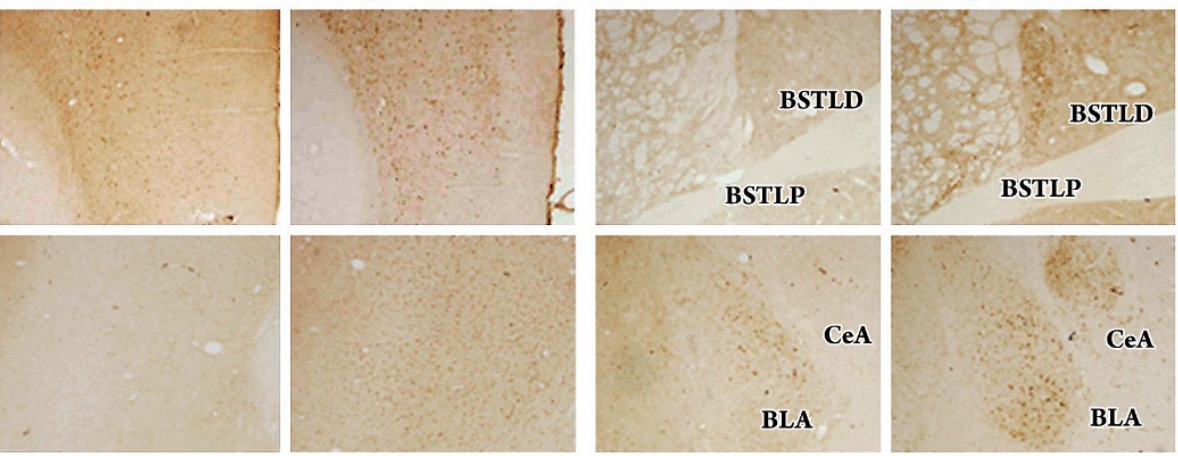

BNST

DLS
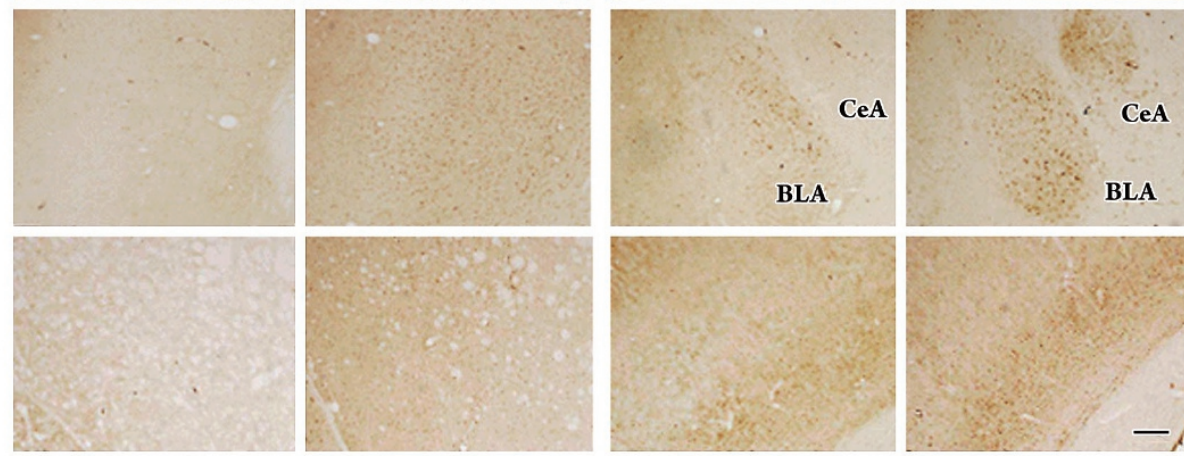

BLA

CeA

B
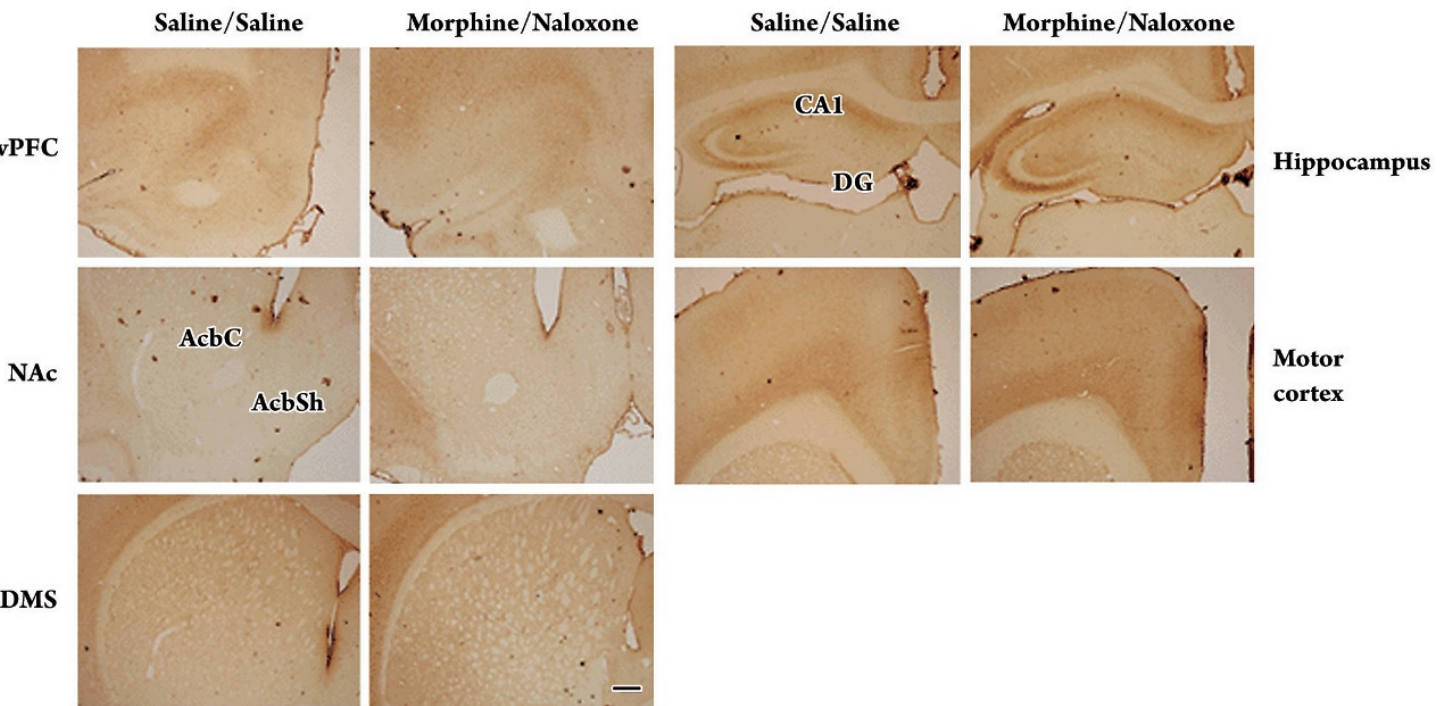

cortex

Figure 3. Mapping of Arc protein expression in different regions of the rat brain after naloxone-precipitated acute morphine withdrawal and place aversion. (A) Areas where significant difference among groups was found. Acute withdrawal induced aversion increased Arc protein in mPFC, IPFC, DLS, CeA, BLA subregions of amygdala, BNST and sensory cortex. Scale bar, $10 \mu \mathrm{m}$. (B) No significant changes of Arc protein expression in vPFC, NAc (AcbC and AcbSh subregions), DMS, hippocampus (CA1 and DG subregions) and motor cortex between control group and acute withdrawal group. Scale bar, $20 \mu \mathrm{m}$. Images after immunohistochemistry showed the expression of Arc protein in the rat brain along the rostrocaudal axis. Withdrawal was precipitated with $0.3 \mathrm{mg} / \mathrm{kg}$ naloxone. The Arc protein expression appeared in dots.

the aversive properties of withdrawal in drug-dependent subjects $^{[2,25]}$. The desire to avoid and escape the aversive consequences of opiate withdrawal may contribute to compulsive drug use ${ }^{[26,27]}$. In rodents, the negative affective component of opiate dependence was reflected by several behavioral alterations ${ }^{[1,5,28]}$. Of these behavioral alterations, CPA is the most sensitive index reflecting the negative motivational state produced by opioid withdrawal in both chronically dependent animals ${ }^{[3]}$ and acutely dependent animals ${ }^{[4-7]}$.
Addiction is associated with neuroplasticity in the brain circuitry. Modulation of the expression of immediate early genes (eg, c-fos, and zif268) in certain brain regions may be involved in the alteration of neuroplasticity by addictive drugs ${ }^{[7,29]}$. Increasing evidence suggests that Arc is critically involved in processes of synaptic plasticity that are induced by activity and some forms of behavioral memory ${ }^{[17]}$. A specialized role of Arc in synaptic plasticity is implied by the fact that Arc mRNA is enriched in dendrites of neurons ${ }^{[18]}$ and its 
A

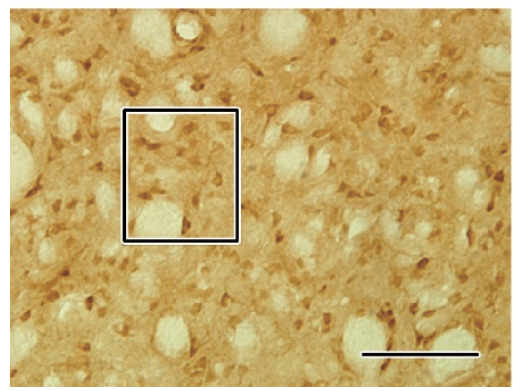

B

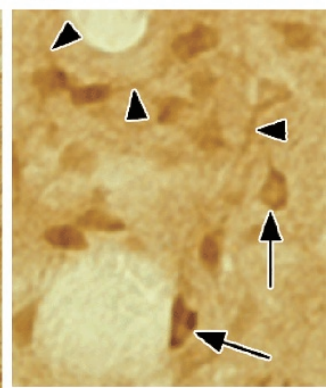

Figure 4. A and B: photomicrographs illustrated Arc immunostaining in neurons of the striatum following naloxone induced acute withdrawal. The cell bodies and dendrites of neurons were stained. In B, arrows indicated cell bodies and arrowheads indicated dendrites. Scale bar, $10 \mu \mathrm{m}$.

mRNA and protein accumulate in dendrites at sites of recent synaptic activity ${ }^{[19]}$. These findings suggest that Arc could be used as a molecular marker to map the neural substrates that are recruited by various stimuli. In the present study, we revealed strikingly different activation of brain areas by conditioned drug withdrawal in acute morphine-dependent rats using quantitative immunohistochemical analysis of the
Arc protein expression, which suggests that the PFC (mPFC, IPFC), striatum (DLS), amygdala (CeA, BLA), BNST and sensory cortex may be crucially involved in the formation of the negative withdrawal memory, leading to CPA behaviors when animals are re-exposed to the paired environment.

PFC plays an important role in a variety of cognitive and executive processes, including working memory, planning and decision making, and behavior inhibition ${ }^{[30]}$. It is also important for addiction-related behaviors such as impulsive $e^{[31]}$ and reward-related learning ${ }^{[32]}$. PFC can be divided into three distinct subregions in rats: $\mathrm{MPFC}, \mathrm{PFF}$, and $\mathrm{vPFC}^{[32]}$. PFC is a richly interconnected system with widespread projections to and from almost all other parts of the brain ${ }^{[32,33]}$ and forms a neural circuit implicated in certain cognitive and emotional processes ${ }^{[34]}$. In this study, we found that Arc expression was significantly elevated in both $\mathrm{mPFC}$ and $\mathrm{PFC}$ in withdrawal rats, suggesting that these two regions were co-activated by morphine withdrawal. This finding is consistent with the emerging evidence that there are functional interactions between $\mathrm{MPFC}$ and $\mathrm{IPFC}^{[35]}$. The increase of Arc in the MPFC and IPFC may explain the fact that conditioned withdrawal rats could easily identify the naloxone-paired environment and showed a strong aversion
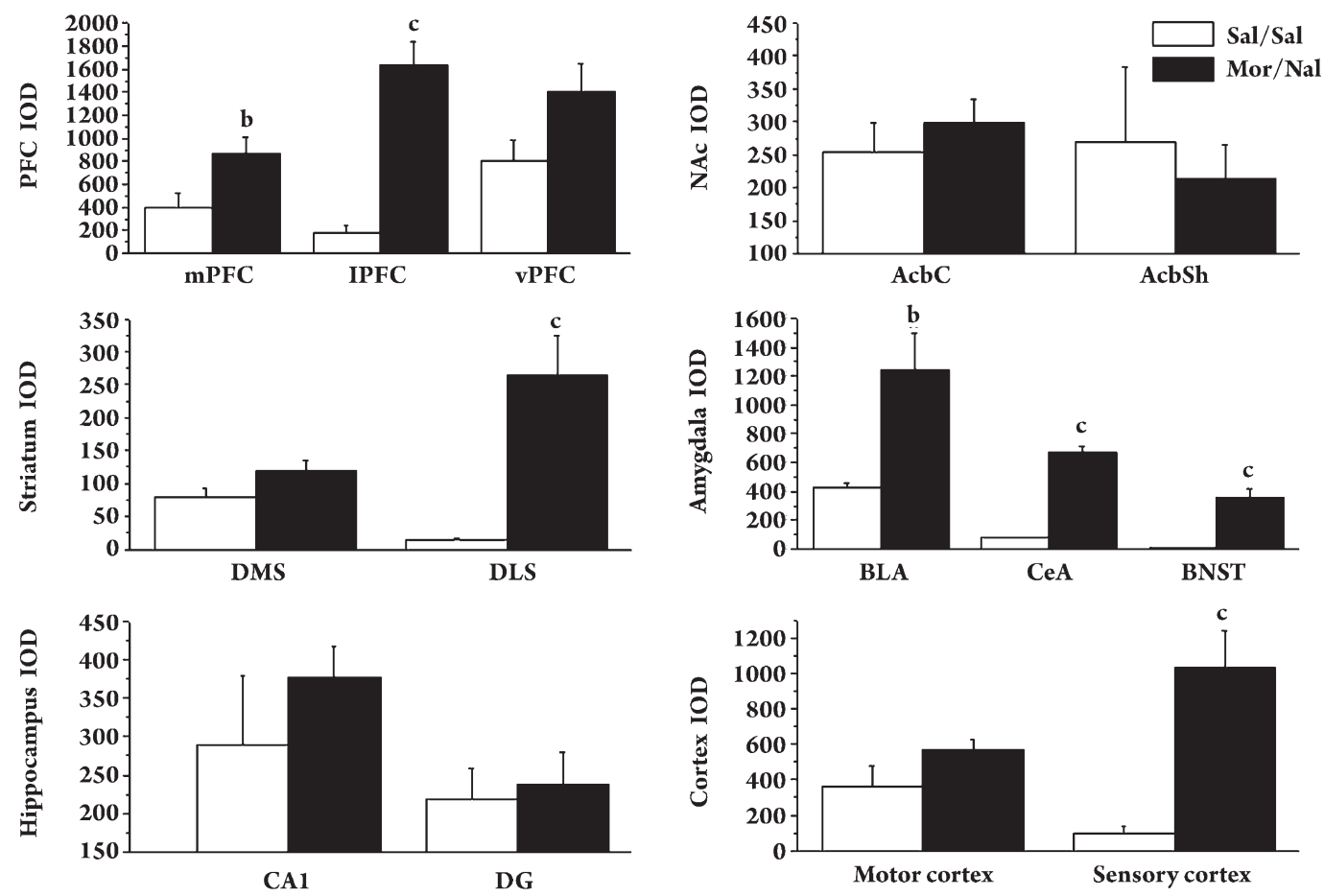

Figure 5. Influence of acute morphine withdrawal on Arc protein expression in rats' different brain regions of the CPA model. Integrated optical density (IOD) values were measured of the Arc expression. We found marked up-regulation of Arc protein level in the mPFC and $1 P F C$, the lateral striatum, the BLA, CeA subregions of amygdala, BNST and the sensory cortex of naloxone treated rats. Bars indicated mean \pm SEM. $n=4$. ${ }^{b} P<0.05$, ${ }^{c} P<0.01$ significant different between saline/saline-paired and morphine/naloxone-paired rats. 


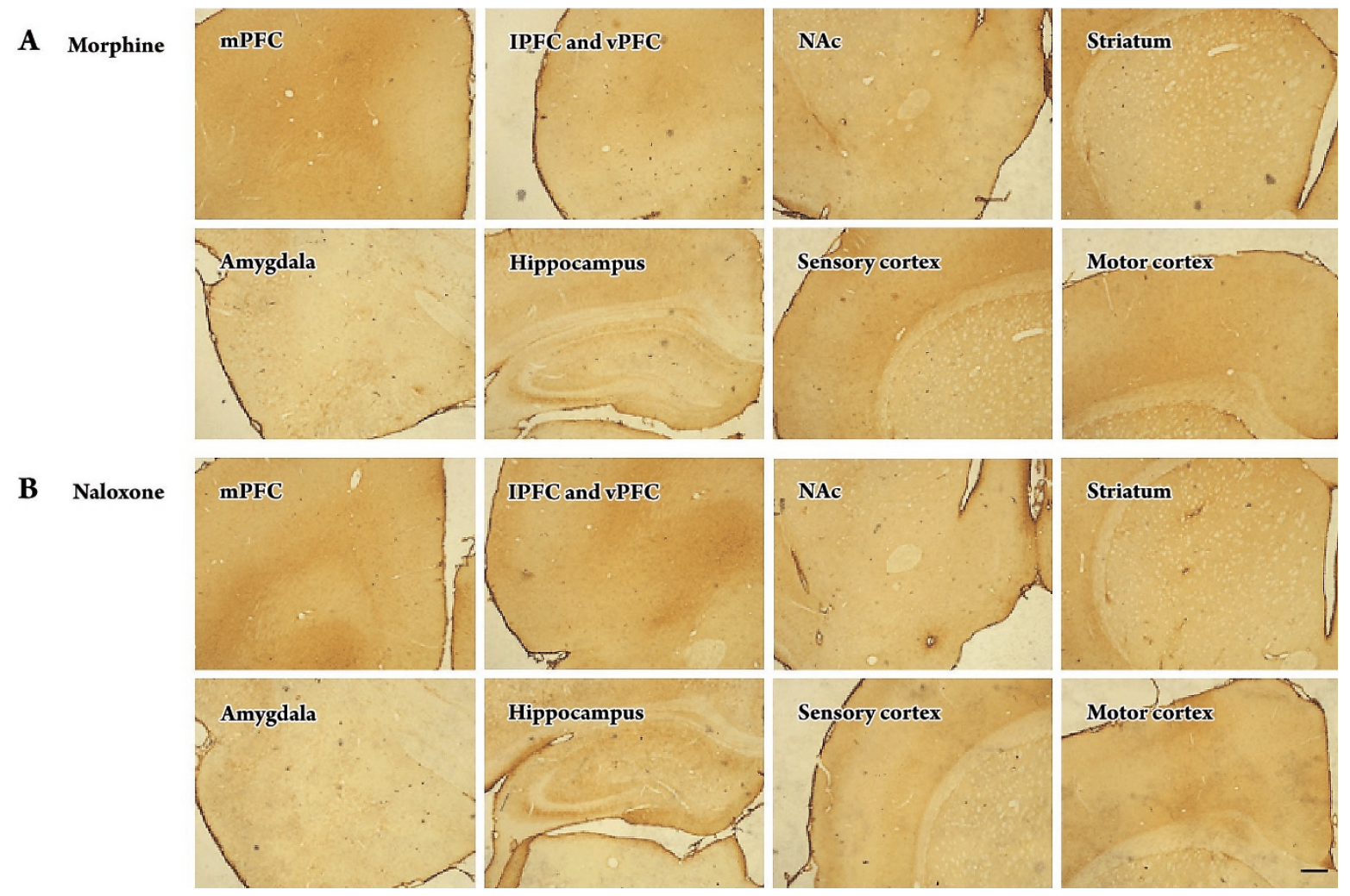

Figure 6. The expression of Arc protein in different brain areas after single morphine $(10 \mathrm{mg} / \mathrm{kg}$ ) or single naloxone $(0.3 \mathrm{mg} / \mathrm{kg})$ treatment. (A) At $4.5 \mathrm{~h}$ after morphine injection, we could hardly find positive cells of Arc protein. (B) Little positive cells of Arc protein were found in the brain at $30 \mathrm{~min}$ after naloxone injection. Scale bar, $20 \mu \mathrm{m}$.

to it because this cognitive ability requires the function of PFC. Therefore, $\mathrm{mPFC}$ and $\mathrm{IPFC}$ may be implicated in the formation of withdrawal memories. The remarkable increase of Arc protein also occurred in the sensory cortex, suggesting that this region was also involved in the formation of withdrawal memories.

The mammalian striatum is an important brain structure that is involved in controlling behavior output. It is generally divided into three regions: dorsal striatum, ventral striatum (nucleus accumbens, NAc), and olfactory tubercle ${ }^{[36]}$. In instrumental conditioning, procedural memory is often thought to depend on the integrity of the dorsal striatum, particularly of the lateral region of this area (DLS), which receives massive excitatory projections from the sensorymotor cortices and influences various motor systems via its projections to the brainstem and the motor thalamocortical pathways ${ }^{[37]}$. This study revealed that Arc remarkably increased in DLS but not in DMS following morphine withdrawal, supporting the involvement of DLS in habit learning and in the formation of persistent drug-related habits ${ }^{[38]}$. The activation of DLS by withdrawal suggests that this region might be involved in the negative reinforcing effect of abuse drugs.

The amygdala is a forebrain structure composed of several distinct subnuclei including CeA and BLA. Bed nucleus of the stria terminalis (BNST) is a component of the extended amygdala ${ }^{[39]}$. These brain regions are thought to be a key neural substrate underlying emotional responses such as anxiety and fear in both humans and animals ${ }^{[40]}$ and are suggested to be involved in both the acute positive reinforcing effects of abuse drugs and the negative reinforcing effect associated with drug withdrawal ${ }^{[41,42]}$. Studies using brain lesions, intracerebral injections of opiate antagonists or immediate-early genes as markers of neuronal reactivity have shown that the negative motivational component of opioid withdrawal appears to be centrally mediated by the amygdala ${ }^{[3,43]}$ and BNST ${ }^{[44-46]}$. The present study showed that morphine withdrawal elicited a significant increase in Arc protein expression in the CeA, BLA and BNST, suggesting that these brain regions might play important roles in the negative affective aspect of morphine withdrawal, which led to the induction of CPA behaviors in acutely dependent rats. 
NAc is a key neural substrate that is implicated in reward learning and drug addiction ${ }^{[32,47]}$. However, we did not detect a difference in Arc expression in NAc compared with saline-treated rats. In addition, we also failed to detect changes in Arc expression in the hippocampus. These results are distinct from previous observations employing the $\mathrm{c}$-fos gene as a marker of neuronal reactivity to map the neural substrates that are recruited by conditioned drug withdrawal from chronic morphine-dependent rats ${ }^{[45,46]}$. The discrepancy may be because our experiments differ in many ways, including: (1) the type of dependence (acute $v s$ chronic); (2) the immediate early gene used as a molecular marker (Arc vs c-fos); and (3) test time after withdrawal.

All together, increasing evidence demonstrates that avoidance of the aversive aspects of opiate withdrawal is a significant motivating factor for drug seeking in addicts. Therefore, our results indicate that the PFC (mPFC, $1 \mathrm{PFC})$, striatum (DLS), amygdala (CeA, BLA), BNST and sensory cortex may be important components of brain regions involved in the maintenance of drug use and addictive behavior.

\section{Acknowledgement}

This study was supported by the National Basic Research Program grant from the Ministry of Science and Technology of China (№ G2003CB515400) and (№ 2009CB522000), the National Science Fund for Distinguished Young Scholars from the National Natural Science Foundation of China (№ 30425002), and a fund granted by the Chinese Academy of Sciences (№ KSCXI/YW/R/68).

\section{Author contributions}

$\mathrm{Mu} \mathrm{LI}$ designed and performed the research and wrote the paper; Bin LU assisted in the research and data analysis; Yuan-yuan HOU and Jie CHEN helped with animal training; Zhi-qiang CHI provided consultation; Jing-gen LIU designed the research and revised the paper.

\section{References}

1 Higgins GA, Sellers EM. Antagonist-precipitated opioid withdrawal in rats: evidence for dissociations between physical and motivational signs. Pharmacol Biochem Behav 1994; 48: 1-8.

2 Koob GF. Neurobiology of addiction. Toward the development of new therapies. Ann N Y Acad Sci 2000; 909: 170-85.

3 Stinus L, Le Moal M, Koob GF. Nucleus accumbens and amygdala are possible substrates for the aversive stimulus effects of opiate withdrawal. Neuroscience 1990; 37: 767-73.

4 Azar MR, Jones BC, Schulteis G. Conditioned place aversion is a highly sensitive index of acute opioid dependence and withdrawal. Psychopharmacology 2003; 170: 42-50.

5 Parker LA, Cyr JA, Santi AN, Burton PD. The aversive properties of acute morphine dependence persist $48 \mathrm{~h}$ after a single exposure to morphine: evaluation by taste and place conditioning. Pharmacol Biochem Behav 2002; 72: 87-92.

6 White DA, Hwang ML, Holtzman SG. Naltrexone-induced conditioned place aversion following a single dose of morphine in the rat. Pharmacol Biochem Behav 2005; 81: 451-8.

7 Jin C, Araki H, Hagata M, Suemaru K, Shibata K, Kawaski H, et al. Withdrawal-induced c-Fos expression in the rat centromedial amygdala $24 \mathrm{~h}$ following a single morphine exposure. Psychopharmacology 2004; 175: 428-35.

8 Hyman SE, Malenka RC, Nestler EJ. Neural mechanisms of addiction: the role of reward-related learning and memory. Annu Rev Neurosci 2006; 29: 565-98.

9 Kuipers SD, Bramham CR. Brain-derived neurotrophic factor mechanisms and function in adult synaptic plasticity: new insights and implications for therapy. Curr Opin Drug Discov Devel 2006; 9: 580-6.

10 Abraham WC, Mason SE, Demmer J, Williams JM, Richardson $\mathrm{CL}$, Tate WP, et al. Correlations between immediate early gene induction and the persistence of long-term potentiation. Neuroscience 1993; 56: 717-27.

11 Worley PF, Bhat RV, Baraban JM, Erickson CA, McNaughton BL, Barnes CA. Thresholds for synaptic activation of transcription factors in hippocampus: correlation with long-term enhancement. J Neurosci 1993; 13: 4776-86.

12 Hess US, Lynch G, Gall CM. Regional patterns of c-fos mRNA expression in rat hippocampus following exploration of a novel environment versus performance of a well-learned discrimination. J Neurosci 1995; 15: 7796-809.

13 Nagahara AH, Handa RJ. Fetal alcohol exposure alters the induction of immediate early gene mRNA in the rat prefrontal cortex after an alternation task. Alcohol Clin Exp Res 1995; 19: 1389-97.

14 Vann SD, Brown MW, Erichsen JT, Aggleton JP. Using fos imaging in the rat to reveal the anatomical extent of the disruptive effects of fornix lesions. J Neurosci 2000; 20: 8144-52.

15 Seeds NW, Williams BL, Bickford PC. Tissue plasminogen activator induction in Purkinje neurons after cerebellar motor learning. Science 1995; 270: 1992-4.

16 Link W, Konietzko U, Kauselmann G, Krug M, Schwanke B, Frey $\mathrm{U}$, et al. Somatodendritic expression of an immediate early gene is regulated by synaptic activity. Proc Natl Acad Sci USA 1995; 92: 5734-8.

17 Tzingounis AV, Nicoll RA. Arc/Arg3.1: linking gene expression to synaptic plasticity and memory. Neuron 2006; 52: 403-7.

18 Lyford GL, Yamagata K, Kaufmann WE, Barnes CA, Sanders LK, Copeland NG, et al. Arc, a growth factor and activity-regulated gene, encodes a novel cytoskeleton-associated protein that is enriched in neuronal dendrites. Neuron 1995; 14: 433-45.

19 Steward O, Wallace CS, Lyford GL, Worley PF. Synaptic activation causes the mRNA for the IEG Arc to localize selectively near activated postsynaptic sites on dendrites. Neuron 1998; 21: 74151.

20 Mucha RF, Walker MJ. Aversive property of opioid receptor blockade in drug-naive mice. Psychopharmacology (Berl) 1987; 93: 483-8. 
21 Guzowski JF, Setlow B, Wagner EK, McGaugh JL. Experiencedependent gene expression in the rat hippocampus after spatial learning: a comparison of the immediate-early genes Arc, c-fos, and zif268. J Neurosci 2001; 21: 5089-98.

22 Kelly MP, Deadwyler SA. Experience-dependent regulation of the immediate-early gene arc differs across brain regions. J Neurosci 2003; 23: 6443-51.

23 McIntyre CK, Miyashita T, Setlow B, Marjon KD, Steward O, Guzowski JF, et al. Memory-influencing intra-basolateral amygdala drug infusions modulate expression of Arc protein in the hippocampus. Proc Natl Acad Sci USA 2005; 102: 10718-23.

24 Hutcheson DM, Everitt BJ, Robbins TW, Dickinson A. The role of withdrawal in heroin addiction: enhances reward or promotes avoidance? Nat Neurosci 2001; 4: 943-7.

25 Rodríguez de Fonseca F, Navarro M. Role of the limbic system in dependence on drugs. Ann Med 1998; 30: 397-405.

26 Koob GF. Drug addiction: the yin and yang of hedonic homeostasis. Neuron 1996; 16: 893-6.

27 Bechara A, Nader K, van der Kooy D. A two-separate-motivational-systems hypothesis of opioid addiction. Pharmacol Biochem Behav 1998; 59: 1-17.

28 Schaefer GJ, Michael RP. Changes in response rates and reinforcement thresholds for intracranial self-stimulation during morphine withdrawal. Pharmacol Biochem Behav 1986; 25: 1263-9.

29 Thomas KL, Arroyo M, Everitt BJ. Induction of the learning and plasticity-associated gene Zif268 following exposure to a discrete cocaine-associated stimulus. Eur J Neurosci 2003; 17: 1964-72.

30 Dalley JW, Cardinal RN, Robbind TW. Prefrontal executive and cognitive functions in rodents: neural and neurochemical substrates. Neurosci Biobehav Rev 2004; 28: 771-84.

31 Jentsch JD, Taylor JR. Impulsive resulting from frontostriatal dysfunction in drug abuse: implications for the control of behavior by reward-related stimuli. Psychopharmacology 1999; 146: 37390.

32 Cardinal RN, Parkinson JA, Hall J, Everitt BJ. Emotion and motivation: the role of the amygdala, ventral striatum, and prefrontal cortex. Neurosci Biobehav Rev 2002; 26: 321-52.

33 Ridderinkhof KR, Van den Wildenberg WP, Segalowitz SJ, Carter CS. Neurocognitive mechanisms of cognitive control: the role of prefrontal cortex in action selection, response inhibition, performance monitoring, and reward-based learning. Brain Cogn 2004; 56: 129-40.
34 Floresco SB, Tse MT. Dopaminergic regulation of inhibitory and excitatory transmission in the basolateral amygdale-prefrontal cortical pathway. J Neurosci 2007; 27: 2045-57.

35 Ridderinkhof KR, Ullsperger M, Crone EA, Nieuwenhuis S. The role of the medial frontal cortex in cognitive control. Science 2004; 306: 443-7.

36 Voorn P, Vanderschuren LJMJ, Groenewegen HJ, Robbins TW, Pennartz CMA. Putting a spin on the dorsal-ventral divide of the striatum. Trends Neurosci 2004; 27: 468-74.

37 Wickens JR, Reynolds JN, Hyland BI. Neural mechanisms of reward-related motor learning. Curr Opin Neurobiol 2003; 13: 685-90.

38 Gerdeman GL, Partridge JG, Lupica CR, Lovinger DM. It could be habit forming: drugs of abuse and striatal synaptic plasticity. Trends Neurosci 2003 ; 26: 184-92.

39 Alheid GF, Beltramino CA, De Olmos JS, Forbes MS, Swanson DJ, Heimer L. The neuronal organization of the supracapsular part of the stria terminalis in the rat: the dorsal component of the extended amygdala. Neuroscience 1998; 84: 967-96.

40 Gallagher M, Chiba AA. The amygdala and emotion. Curr Opin Neurobiol 1996; 6: 221-7.

41 Koob GF. The role of the striatopallidal and extended amygdala systems in drug addiction. Ann N Y Acad Sci 1999; 877: 445-60.

42 Koob GF, Le Moal M. Drug addiction, dysregulation of reward, and allostasis. Neuropsychopharmacology 2001; 24: 97-129.

43 Heinrichs SC, Menzaghi F, Schulteis G, Koob GF, Stinus L. Suppression of corticotropin-releasing factor in the amygdala attenuates aversive consequences of morphine withdrawal. Behav Pharmacol 1995; 6: 74-80.

44 Delfs JM, Zhu Y, Druhan JP, Aston-Jones G. Noradrenaline in the ventral forebrain is critical for opiate withdrawal-induced aversion. Nature 2000; 403: 430-4.

45 Frenois F, Cador M, Caillé S, Stinus L, Le Moine C. Neural correlates of the motivational and somatic components of naloxoneprecipitated morphine withdrawal. Eur J Neurosci 2002; 16: 1377-89.

46 Frenois F, Stinus L, Di Blasi F, Cador M, Le Moine CA. Specific limbic circuit underlies opiate withdrawal memories. J Neurosci 2005; 25: 1366-74.

47 Day JJ, Carelli RM. The nucleus accumbens and Pavlovian reward learning. Neuroscientist 2007; 13: 148-59. 